\title{
Educação e branquitude: uma discussão com professores da educação básica
}

\section{Resumo}

O objetivo central do presente estudo é mapear e problematizar discursos e representações recorrentes acerca da diferença racial e da Branquitude em entrevistas com sete professores que atuavam na educação básica da rede pública municipal de Sapucaia do Sul/RS, entre os anos de 2016 e 2017, a partir das provocações de dois curtas- metragens: "Cores e Botas" e "Pode me chamar de Nadí", disponíveis no YouTube. As análises apresentadas são realizadas na perspectiva teórica dos Estudos Culturais em Educação, a partir dos conceitos de representação, identidade e Branquitude. Entre os resultados, destaca-se que nas narrativas dos docentes entrevistados, as representações mais recorrentes foram representações racializadas marcadas pelos discursos da democracia racial e da mestiçagem e mediadas pelas noções de Branquitude. Salienta-se ainda, que as narrativas fílmicas contribuíram para tensionar as representações racializadas e os privilégios da branquitude no âmbito da educação básica e para problematizar padrões estéticos eurocêntricos associados particularmente ao tipo de cabelo, como símbolo de identidade étnico-racial.

Palavras-chave: Educação. Branquitude. Entrevistas. Professores.
Maria Angélica Zubaran

Doutora em História pela State University of New York at Stony

Brook, USA. Professora da Universidade Luterana do Brasil ULBRA.

Brasil

angelicazubaran@yahoo.com.br

Joice Mari Ferreira da Cruz

Mestre em Educação pela

Universidade Luterana do Brasil -

ULBRA. Professora na Rede

Municipal de Sapucaia do Sul-RS.

Brasil

joiceaqui@hotmail.com

\section{Para citar este artigo:}

ZUBARAN, Maria Angélica; CRUZ, Joice Mari Ferreira da. Educação e branquitude: uma discussão com professores da educação básica. Revista PerCursos, Florianópolis, v. 20, n.44, p. 138 - 154, set./dez. 2019. 


\title{
Education and whiteness: a discussion with basic education teachers
}

\begin{abstract}
The main goal of this paper is to map and problematize recurrent discourses and representations about racial difference and whiteness in interviews with seven teachers who worked in basic education in the municipal public schools system of Sapucaia do Sul, RS, Brazil, between the years 2016 and 2017, from two short films "Cores e Botas" and "Pode me chamar de Nadí", available on Youtube. The analyses presented are carried out in the theoretical perspective of Cultural Studies in Education, based on the concepts of representation, identity, and whiteness. Among the results, it is noteworthy that in the narratives of the interviewed teachers, the recurring representations were racialized representations marked by the discourses of racial democracy and miscegenation and mediated by the notions of whiteness. It should also be noted that the filmic narratives contributed to tension the racialized representations and the privileges of whiteness in the scope of basic education and to problematize Eurocentric aesthetic patterns associated particularly with the type of hair, as a symbol of ethnicracial identity.
\end{abstract}

Keywords: Education. Whiteness. Interviews. Teachers. 


\section{Introdução}

O presente estudo analisa e problematiza discursos e representações recorrentes sobre a diferença racial e a Branquitude em entrevistas realizadas com sete professores da educação básica: quatro professoras dos anos iniciais e duas professoras e um professor dos anos finais, em quatro escolas públicas municipais da cidade de Sapucaia do Sul, localizadas na região metropolitana de Porto Alegre/RS. Destaca-se que o período de docência dos entrevistados varia entre um mínimo de seis e o máximo de vinte e quatro anos. Quanto à idade dos entrevistados, varia entre trinta e um e cinquenta e três anos de idade. Todos possuem formação superior.

Os professores foram entrevistados a partir da visualização de dois curtasmetragens: "Cores e Botas" e "Pode me chamar de Nadí", selecionados como deflagradores das entrevistas e como ferramentas pedagógicas que contribuem para a construção de uma educação antirracista na escola básica. A coleta dos dados empíricos ocorreu entre 2016 e 2017. Para preservar a imagem dos (as) entrevistados (as) foram utilizados pseudônimos para nomeá-los. As entrevistas são apresentadas por meio de excertos das falas dos professores, em caixas de texto.

O primeiro curta metragem, "Cores e Botas", é dirigido por Juliana Vicente, produzido em 2010, com duração de quinze minutos. metragem filme conta a história de Joana, uma menina negra de família de classe média, que sonha em ser "paquita”, auxiliar da apresentadora brasileira Xuxa Meneghel, em seu programa televisivo infantil. Joana participa de um concurso para ser "paquita" na escola em que estuda. O filme discute os padrões estéticos produzidos e disseminados pela mídia televisiva, a manutenção e reprodução desses padrões na escola, as representações racializadas que circulam na cultura e suas implicações na construção de subjetividades e identidades infanto-juvenis. Joana, a protagonista, assim como muitas meninas que tiveram sua infância nos anos 80 , é incentivada pelos pais a perseguir seus ideais e a conquistar seus objetivos através do esforço individual. Entretanto, os pais de Joana demonstram dificuldade em reconhecer o preconceito racial na escola e o fato de que sua filha teria sido rejeitada no teste para “paquita” em razão de suas características fenotípicas, que não se enquadram no padrão 
branco predominante do programa de Xuxa, em que a apresentadora, assim como as “paquitas”, são loiras, como em muitos outros programas da mídia. O filme provoca reflexões sobre padrões estéticos e, particularmente, sobre privilégios brancos, demonstrando o quanto as marcas impressas nos corpos ainda são fatores que limitam as oportunidades de indivíduos considerados fora dos padrões hegemônicos.

O segundo curta metragem, "Pode me chamar de Nadî", dirigido por Déo Cardoso, produzido em 2009, tem duração de vinte minutos e conta a história de Nadí, uma menina negra, moradora da periferia, que tem vergonha de seus cabelos crespos. $O$ filme salienta as dificuldades de Nadí em aceitar seus cabelos, que são motivo de chacota dos meninos da vizinhança. Nadí, assim como muitas meninas de cabelos crespos e cacheados, não gosta de seus cabelos e tenta escondê-los com o uso de um boné. Ela procura fazer amizade com meninos da vizinhança, mas não é bem recebida - pelo contrário, os meninos zombam de seu cabelo e pegam seu boné, que vai parar no carrinho de um vendedor ambulante, que se recusa a devolvê-lo. Nadí tenta sem sucesso recuperar o boné e o substitui por uma bandana. Então ela conhece Laila, uma modelo negra, que aguardava o ônibus em uma parada. Laila conversa com Nadí sobre o seu cabelo e mostra que não há motivo para escondê-lo, afirmando que ela tinha um cabelo bonito e sugere usá-lo solto. Nadí decide deixar seus cabelos crespos soltos, colocando sobre o cabelo uma flor de crochê que recebeu de presente de Laila. No final do curta, Nadí já não faz mais questão de recuperar seu boné.

A pertinência desta pesquisa está relacionada às Políticas de Ações Afirmativas, particularmente, às leis 10.639/2003 e 11.645/2008 e às Diretrizes Curriculares para o Estudo das Relações Étnico-Raciais (2004), que resultaram da ação do Movimento Negro e de uma intelectualidade negra e indígena, que tornaram obrigatória a inclusão da História da África e da Cultura Afro-Brasileira e Indígena no currículo escolar das escolas públicas e particulares de educação básica, no combate ao racismo e à discriminação racial e na defesa da igualdade de direitos e oportunidades aos negros e indígenas como cidadãos brasileiros.

Vale destacar ainda que as narrativas docentes são consideradas na perspectiva de Silveira (2007) e Andrade (2012), que entendem as entrevistas como eventos discursivos 
complexos, permeados pelas relações de poder entre entrevistador e entrevistado. As autoras concordam que as entrevistas são marcadas por disputas e negociações que questionam a suposta neutralidade e objetividade dessas narrativas, consideradas na sua historicidade. Silveira e Andrade têm como referências teóricas análises da Sociolinguística Interacional, da Antropologia e dos Estudos Culturais. Nesta perspectiva, as autoras entendem que as entrevistas são forjadas pelas interações e situações de trocas entre entrevistador e entrevistado, como um jogo interlocutivo com múltiplas dimensões e significados. A presente análise compartilha desse entendimento.

Em termos teóricos, parte-se ainda dos pressupostos dos Estudos Culturais em Educação e da chamada virada linguística, cujas perspectivas consideram a centralidade da cultura e o papel constitutivo da linguagem na produção de significados, entendidos como fluidos e contingentes e considerados na sua historicidade. Salienta-se o entendimento de que os discursos e representações contidos na linguagem possuem um potencial pedagógico que contribui para a formação e constituição de sujeitos, ensinando-os a conduzirem suas condutas e disseminando modos de ser e de estar no mundo. Neste sentido, os conceitos de representação e identidade são centrais para as análises, assim como o conceito de Branquitude.

Conforme argumenta Hall (2016), a representação é uma parte essencial do processo pelo qual os significados são produzidos e compartilhados na cultura. Neste sentido, o autor destaca que a linguagem é a forma pela qual os indivíduos de uma mesma cultura compartilham suas emoções, conceitos, imagens e ideias e através da qual se interpreta o mundo por meio de "códigos culturais".

Quanto ao conceito de identidade, Hall (2011, p. 10-13) argumenta que as identidades nas sociedades da modernidade tardia se encontram em constante mudança, dependendo das formas pelas quais somos representados ou interpelados nos sistemas culturais em que estamos inseridos. Portanto, importa destacar que a construção das identidades está relacionada às formas pelas quais os sujeitos são interpelados ou representados nos diversos artefatos culturais e que não são automáticas, mas podem ser ganhas ou perdidas. Também Silva (2000) argumenta que é através da representação que a identidade e a diferença passam a existir. Para o autor, as identidades são 
construídas através de oposições binárias e de forma contrastante, estabelecendo-se então o que elas são a partir do que elas não são. Segundo o autor, a marcação da diferença é imposta, disputada, através de oposições binárias, que estão em estreita relação com as relações de poder (SILVA, 2000, p. 50).

Já sobre o conceito de Branquitude, apropriamo-nos das discussões de autores como Edith Piza, Liv Sovik, Lourenço Cardoso e Lia Vainer Schucman. Segundo Piza (2000), no Brasil pouco se tem explorado os significados das identidades brancas. A autora argumenta que é necessário que se discuta sobre as representações de Branquitude e sobre os privilégios de ser branco, pois a noção de raça não é instigada ou desenvolvida entre estes sujeitos. Piza argumenta que as pesquisas sobre as relações raciais no Brasil frequentemente salientam o legado da escravidão como explicativos da pobreza e da falta de representação de negros(as) na sociedade, mas pouco ou nada questionam sobre a relação dos brancos com as mazelas dessa violência.

Por outro lado, Sovik (2009), em seus estudos sobre a Branquitude, enfatiza que não há constrangimento entre as pessoas consideradas brancas no que diz respeito à forma como são representadas como o padrão "ideal”. Neste sentido, a autora defende a necessidade de observarmos as representações de Branquitude no contexto de diversos discursos disseminados na cultura, particularmente, nos meios de comunicação, em que sujeitos com características consideradas europeias são representados como o ideal de beleza, comportamento e status social, contribuindo para a exclusão de sujeitos não brancos.

Também Schucman (2012) e Cardoso (2014) salientam os privilégios raciais simbólicos e materiais da Branquitude, que posicionam os indivíduos brancos em um lugar superior na hierarquia racial e que resultam em exclusões e discriminações raciais na sociedade brasileira. Essas exclusões, conforme afirmam os autores, constituem o privilégio racial branco. Os teóricos acima discutidos concordam que a Branquitude necessita ser exposta e discutida a fim de visibilizar suas implicações na sociedade, colaborando para a identificação e o questionamento de privilégios, bem como para a construção de uma sociedade mais justa e igualitária para todas as pertenças raciais. 


\section{Representações racializadas e Branquitude}

As narrativas docentes sobre a construção da diferença racial e da Branquitude no

âmbito da escola evidenciaram posicionamentos ambivalentes, ora reconhecendo que alunos brancos têm privilégios na escola, ora reafirmando discursos de democracia racial e de meritocracia e negando e existência de questões raciais na escola. Esses discursos e representações se entrecruzam nas narrativas que, de maneira geral, mantêm a ideia da igualdade universal de oportunidades e de ascensão social para todos os cidadãos brasileiros, independentemente de classe, gênero e cor.

Um exemplo dessas representações relacionadas às noções de democracia racial e meritocracia é a narrativa da professora Amanda, quando refere que seu sobrinho sofre preconceito por ser loiro.

Porque eles dizem "para ti é tudo mais fácil", só que ele estuda muito, ele é dedicado, só que ele sofre preconceito, eles dizem "tu és lindo, tu és loiro, para ti é tudo mais fácil”. Só que não é, nesse caso não. Pode ser que sim, que abra mais portas para ele sim, só que ele também é esforçado, só que tem isso né, as pessoas acham isso porque é isso. (AMANDA) [45 anos, Professora anos iniciais]

Já a professora Sara afirma a inexistência do preconceito na escola em que leciona, mas reconhece que existe preconceito em outras escolas ao seu redor.

(...) aqui no nosso contexto não vejo isso, não percebo isso né... não sei se é porque a escola... o trabalho que é feito aqui... Não se consegue observar isso, existe assim uma igualdade, os professores no geral tratam os alunos nesse sentido assim... no mesmo patamar... em relação à cor, ou até a própria... economicamente né, falando... Eu acho que isso não existe, aqui pelo menos eu não percebo. Outras escolas que eu trabalhei, que eu passei, eu já percebi isso, mas aqui não. (SARA) [53 anos, séries iniciais] 
A fala de Sara encontra amparo nos argumentos de Cardoso quando cita Florestan Fernandes, argumentando que "o brasileiro possui preconceito de ter preconceito", marcando a dificuldade que brasileiros demonstram em assumir seu próprio preconceito. A negação do preconceito racial na escola é também uma estratégia que, de certa forma, isenta os professores de qualquer responsabilidade pelas desigualdades raciais presentes no ambiente escolar.

Schucman (2012, p. 75-76) também chama atenção para o fato de que a ambiguidade é uma das características da Branquitude, uma forma de manutenção dos privilégios brancos, que contribui para a continuidade do racismo e para a negação e invisibilidade desses privilégios na sociedade brasileira. Também Gomes (2007, p. 100) aponta a ambiguidade como sendo característica do racismo brasileiro, como "uma das formas ardilosas do racismo se manter e se expressar". Quando, a partir dos curtasmetragens, discutimos os privilégios brancos, as narrativas docentes revelam uma representação recorrente de Branquitude, que consiste em culpabilizar o outro, não branco, pela sua exclusão social. Contudo, estudos sobre a Branquitude no Brasil destacam que na perspectiva da supremacia branca é o branco que detém o poder de nomear o outro e de excluí-lo.

O excerto da professora Tati exemplifica esse tipo de representação, quando cita o caso de uma aluna negra que, segundo ela, não aceitou a "brincadeira de mosquitinho da dengue"" e se auto excluiu da atividade, referindo que "eles mesmos se excluem, né?"

Tati: Depende em que sentido da exclusão... muitas vezes dependendo a ocasião, a oportunidade, algumas coisas excluem, em outras eu acho que...

Joice: Consegue pensar em algum exemplo?

Tati: Vou dar um exemplo da Paloma. Ela é negra. Então a gente brinca muito com ela por causa do mosquitinho da dengue e aí ela diz que ela não é o mosquito da dengue, porque ela é negra. Na maioria das vezes, eu acho que sim.

Joice: Que sim? Então existe essa exclusão?

Tati: Existe.

\footnotetext{
${ }^{1}$ Conforme a professora, essa brincadeira era costumeiramente realizada com todos os alunos mais magrinhos da turma, desde que a docente trabalhou uma história que trazia o mosquitinho da dengue como protagonista e este era representado com a cor branca.
} 
Joice: Na escola?

Tati: Muitas vezes até por parte dos alunos mesmo né, eles mesmos se excluem né...

(TATI) [47 anos, séries iniciais]

Os autores Duschatzky e Sckliar (2001, p. 121) sublinham que desde a modernidade, um dos modos mais recorrentes de controle do outro e de representação da alteridade é “o outro como fonte de todo o mal”. Também os estudos de Shohat e Stam (2006, p. 53), consideram que a culpabilização do outro é uma das formas de manifestação do racismo moderno.

Nesta direção, Abramowicz (2012, p. 54) destaca que as pesquisas que investigaram a questão da criança negra nos espaços escolares demonstraram que, em geral, professores tendem a reforçar desigualdades e a contribuir para a manutenção do racismo nos processos de socialização de crianças não brancas nas práticas escolares cotidianas.

\section{Representações de Branquitude e padrões de beleza}

Após assistirem aos dois curtas-metragens, os docentes entrevistados foram indagados sobre Branquitude e padrões de beleza na escola. Três professoras, Laura, Elis e Bárbara, destacaram o quanto os padrões de beleza branca são acionados e interiorizados, com efeitos perversos para a construção das subjetividades negras. Elas se referem, principalmente, às representações e práticas relacionadas aos cabelos crespos de meninas negras, que buscam de diversas maneiras "esconder" seus cabelos, representados frequentemente como "cabelo ruim". Neste sentido, Schucman (2012, p. 83) destaca que, apesar do racismo biológico já ter sido desacreditado pela ciência desde o final da Segunda Guerra Mundial, o fenótipo continua sendo o principal marcador da pertença racial no Brasil e as referências aos atributos físicos aparecem de forma mais explícita nas representações pejorativas aos cabelos crespos.

As narrativas que seguem das professoras Elis, Laura e Bárbara demonstram a hegemonia da Branquitude nos padrões estéticos, particularmente no que se refere aos 
cabelos, demonstrando que meninas negras produzem estratégias de controle de seus cabelos crespos na escola para não serem agredidas, de forma semelhante às representações que foram produzidas e disseminadas nos curtas-metragens. As narrativas docentes se referem também a pequenas mudanças nesses padrões, quando reconhecem que, recentemente, algumas meninas estão assumindo padrões de beleza negra e exibindo seus cabelos crespos com orgulho.

No excerto que segue, a professora Elis se refere à rejeição dos cabelos crespos entre meninas negras e às estratégias usadas para dissimulá-los e escondê-los.

Joice: No curta "Pode me chamar de Nadí", os colegas da escola chamam Nadí de cabelo ruim e, ao longo do curta, Nadí mostra que quer esconder seu cabelo com uso de boné ou um pano. Você acha que na sua escola ocorrem cenas parecidas com essa?

Elis: Seguidamente, as meninas entram pingando água dentro da minha sala e elas pedem pra ir no banheiro pra fazer xixi ou pedem pra ir tomar água e a gente nota que elas voltaram com o cabelo molhado... Eu noto que elas tão tentando assim, né, domar o cabelo... Eu noto que elas fazem bastante uso de chapinha, que elas fazem química no cabelo e ainda existe a coisa do cabelo ruim, né? Agora assim ó, nos últimos dois anos que eu tô vendo umas meninas assumirem assim, uns cabelos crespos ah... parece que com mais orgulho. (ELIS) [34 anos, Professora de religião, séries finais]

Também a professora Laura reconhece que suas alunas negras usam de estratégias para dissimular seus cabelos crespos, conforme se pode observar no excerto abaixo:

Laura: Eu nunca vi eles se xingando de forma racista em sala de aula, não estou dizendo que não ocorra, porque quando eu trabalho com eles a questão de brincadeiras e tal, com cor e raça, eles dizem que já fizeram, quando eu pergunto quem é que já fez brincadeira racista e tal, eles levantam a mão, porque claro, eu sou a primeira a levantar a mão, porque é uma coisa cotidiana né, essa briga é cotidiana, eu já fui criança, já tive no meu contexto, eu já fiz, então eu sou a primeira a levantar a mão e aí eles se sentem mais tranquilos e levantam também, então são vários. Mas eu não vi diretamente eles comentando dos cabelos das meninas; mas eu percebo as meninas negras aqui na escola sempre tentando usar o cabelo preso, bem puxadinho assim, sabe? Puxado e amarrado assim, não é nem aqueles penteados afros, algumas usam, mas não é sempre, é bem preso. Já questionei algumas alunas assim né, quando elas vêm de cabelo solto. A gente diz assim, "ah teu cabelo é tão 
bonito, porque que tu não vens com ele solto mais vezes?". "Não, porque ele fica muito alto, porque não dá", porque não sei quê, sabe? Fica dando uma série de desculpas porque aquele cabelo vai ficar diferente, então o diferente vai chamar a atenção e chamar a atenção pode ser fruto do comentário e não é o padrão... e aí sempre muito... os cabelos muito presos. Então eu acho que sim. Acho que ainda há para as mulheres e para as meninas, principalmente negras, uma dificuldade de andar com o cabelo solto e eu percebo olhando as alunas, né? (LAURA) [31 anos, Professora de História, séries finais]

A narrativa que segue da professora Bárbara sobre a sua filha demonstra os sentimentos dos pais, "que não querem que seus filhos sofram" com o racismo na escola e que produzem representações positivas de beleza negra e do orgulho de ser negro (a) para contestar a branconormatividade na escola.

Bárbara: Para a escola ela não vem com o cabelo solto (...) na escola já criticaram, tinha um menino que falou para ela que o cabelo dela era ruim e que não sei o quê e daí ela respondeu: se o meu cabelo fosse ruim eu raspava igual ao teu.

Joice: então ela já está dando as respostas para os comentários que ocorrem!

Bárbara: Sim e eu fico tranquila, às vezes até digo "filha, para que ser tão estúpida?". Mas, por dentro eu estou dizendo “YES, isso mesmo!". E é aquela questão que a gente sempre conversou com ela, quando ela reclamava que: “ai, me chamou de negra!” E nós dizíamos, "mas tu és negra filha, tu és negra igual a tua mãe, ao teu pai, tua vó, teus tios, tu és negra e nós temos que ter orgulho de sermos negros". Hoje ela está com onze anos, mas assim, desde que ela era novinha, quando ela estava com quatro, para entrar para a escola com cinco anos a gente já começou, eu principalmente (...). Porque tu não quer que teus filhos sofram, né, tu queres que eles sempre lidem com isso, sempre colocamos todas as questões disso e daquilo, alertamos e dizemos: "qualquer coisa que teus coleguinhas disserem tens que falar com a professora", então ela sempre levou assim, só que a Sofia nunca teve papas na língua né, nunca (risos), então falavam um negócio e ela já vinha de atravessado, sabes? E daí esse coleguinha nunca mais tocou no assunto.

Bárbara: Nem sempre as famílias lidam bem com isso em casa ou orientam os filhos, as mães dizem para não dar bola, mas eu penso que não é bem assim, machuca, dói; como tu vais dizer para teu filho não dar bola, né? (BÁRBARA) [34 anos, Professora séries finais] 
Nos relatos das professoras Laura, Elis e Bárbara é possível se observar que tanto as alunas negras adolescentes dos anos finais da educação básica quanto a filha da professora Bárbara são marcadas pelas representações racializadas que circulam na mídia e na escola. Elas respondem de diferentes formas ao racismo cotidiano ao qual são expostas, em alguns momentos tentando dissimular o volume do cabelo crespo para se protegerem dos comentários racistas de seus pares ou respondendo às agressões sofridas com afirmação da sua negritude, como ocorre com as protagonistas Joana e Nadí, nos curtas exibidos.

Neste sentido, Gomes (2008) destaca que o cabelo é o símbolo mais evidente da identidade negra e salienta a presença de estratégias de manipulação e domesticação dos cabelos crespos na mídia, frequentemente representados na publicidade de produtos para o cabelo com expressões como "indomáveis", "indisciplinados" e "rebeldes".

O relato que segue, da professora Tati, demonstra o quanto a Branquitude está associada a características eurocêntricas, como por exemplo, o cabelo liso, colaborando na construção de uma imagem negativa daqueles que não possuem tais atributos e impactando negativamente a convivência entre brancos e não brancos na escola. Também Pinho (2004, p. 109-112), em seu estudo sobre a construção de identidades étnico-raciais na Bahia, argumenta que o padrão de beleza eurocêntrico dominante tem contribuído para a estigmatização e "a baixa autoestima, principalmente entre negros jovens". Segue o relato da professora Tati:

Joice: No curta "Pode me chamar de Nadí", os colegas de escola chamam Nadí de cabelo ruim e ao longo do curta Nadí mostra que quer esconder o cabelo com um boné ou um pano, tu achas que na tua escola acontecem cenas como essa?

Tati: Sim.

Joice: Já presenciou?

Tati: Já. O exemplo da Paloma, né... ela vive de boné na cabeça porque ela diz que o cabelo dela é feio, ela diz que é cabelo de negro. Os guris debocham, dão risada do cabelo dela, aí ela vai de boné, eles vão e puxam o boné e ela nunca penteia o cabelo.

Joice: $E$ alguma ação é feita, assim... tu percebes que alguém fala alguma coisa para ela em outro sentido? 
Tati: Olha, eu dentro da sala de aula, ela é minha aluna, e eu dentro da sala de aula sempre procuro dizer para os meninos que não podem fazer isso né, que cada um tem o seu tipo de cabelo, ela tem o tipo de cabelo dela, se ela tem o cabelo que ela não penteia... um dia eu ainda brinquei com ela que eu ia trazer uma escova de presente, ela disse que não precisava porque ela não gostava de pentear o cabelo. (Grifo nosso) (TATI)

A narrativa da professora Tati, quando refere que "traria uma escova para dar de presente" para sua aluna negra, a fim de que penteasse seus cabelos, revela suas próprias representações negativas sobre os cabelos crespos, historicamente desvalorizados e estigmatizados no convívio social dentro e fora da escola. Neste sentido, Duarte (2012) sugere que as representações que as professoras brancas constroem de crianças negras são elaboradas a partir das representações racializadas que circulam e são legitimadas na sociedade brasileira e que constituem o significado de ser negro e de ser branco, acionados nos episódios de conflitos étnico-raciais na escola. Duarte ressalta ainda, que na escola, circulam representações racializadas subliminares que contribuem para naturalizar como verdades padrões estéticos brancos. De acordo com a autora, alguns professores, ainda que sem intenção explícita, tratam as crianças não brancas de forma diferente e desigual.

Também Guizzo (2011, p. 134), quando discute as práticas corporais de embelezamento na educação infantil, argumenta que características fenotípicas e classe social são marcadores potentes, que conferem valores positivos a determinadas crianças e negativos a outras, reforçando representações racializadas. De acordo com Guizzo (2011, p. 69), as representações que temos de beleza na sociedade atual advêm de múltiplos artefatos culturais como outdoors, revistas, jornais, televisão, por meios dos quais determinados padrões são repetidamente reforçados, interpelando os sujeitos na constituição de si mesmos e dos outros.

No excerto que segue, observa-se que quando a professora Sara é questionada sobre a existência de um padrão ideal de beleza, manifesta certo desconforto, afirmando “que existe gosto para tudo, né?”. Sua narrativa está também marcada pelo discurso da democracia racial, quando refere que "há oportunidades para qualquer tipo de raça". 
Joice: Na parada de ônibus, uma moça negra, modelo, senta ao lado de Nadí e a incentiva a deixar os cabelos soltos, dizendo: "teu cabelo é lindo, devia usar ele sempre solto". Como tu explica essa afirmativa? De que padrão de beleza essa modelo está falando?

Sara: Que existe gosto para tudo, né? E oportunidades para qualquer tipo de raça. Acho que desse padrão que ela fala né, que a beleza não é só o exterior também, de repente o interior, que também a cor não quer dizer nada. Podem ter pessoas que são brancas belas, como negras também, acho que esse padrão é em relação a isso.

Joice: E no fim do curta, quando Nadí deixa seu boné caído na rua, o que mudou na cabeça dela?

Sara: Ela entendeu que ela também poderia ser bela né, mesmo dentro da cor dela, que ela poderia também mostrar a beleza dela, não teria o porquê de estar escondendo aquilo ali, aquela beleza que ela também teria. Acho que foi uma forma de se libertar até de todo aquele preconceito que já vinha em redor dela ali desde o nascimento. (Grifo nosso) (SARA)

Pinho (2004, p. 120) problematiza que, assim como outros valores presentes em nossa sociedade, a beleza e seu oposto, a feiura, são construídos socialmente e compartilhados na cultura. Neste sentido, a autora salienta que a construção cultural do que é belo expressa relações de poder, construídas de forma relacional e hierárquica, que implicam também na construção do seu oposto, o feio. A partir dessa perspectiva, é possível entender melhor o comportamento das protagonistas dos curtas-metragens, que demonstram dificuldade de aceitar seus cabelos crespos.

$\mathrm{Na}$ abordagem teórica dos Estudos Culturais, as concepções de beleza são compreendidas como construídas de forma compartilhada na cultura, por meio de sistemas de representação que vão constituindo modos de ser e agir nos mais variados espaços sociais em que nos inserimos - por exemplo, na mídia cinematográfica e nos espaços escolares. Nesta perspectiva, entende-se que a construção de identidades e diferenças está relacionada ao processo de classificação em oposições binárias, que ordena o mundo social, por meio de relações hierárquicas de poder, excluindo aqueles que não possuem os atributos considerados padrão. Nesta ótica, o feio e o bonito constituem exemplos da estrutura de classificação binária e desigual de representação, produzidas e disseminadas na cultura, em diferentes artefatos culturais e que nos interpelam e nos ensinam a hierarquizar e atribuir diferentes valores aos corpos e aos 
cabelos. A partir dessas premissas, pode-se melhor entender as falas das protagonistas Joana e Nadí, em “Cores e Botas" e "Pode me chamar Nadí", assim como as narrativas de professores da educação básica da zona metropolitana de Porto Alegre/RS, após terem sido desafiados a pensar sobre a construção da diferença racial e da Branquitude na educação básica.

\section{Considerações parciais e provisórias}

Entre os resultados deste estudo foi possível observar que as representações mais recorrentes sobre a diferença racial nas narrativas dos docentes entrevistados foram marcadas pelos discursos da democracia racial e da mestiçagem e mediadas pelas noções de Branquitude disseminadas na mídia impressa e televisiva.

Entretanto, as análises realizadas demonstraram que as identidades étnico-raciais podem ser contestadas e reconfiguradas no âmbito da educação básica, corroborando os estudos de Piza (2000), Sovik (2009), Schucman (2012) e Cardoso (2014), entre outros, quando destacam que a Branquitude não possui um significado intrínseco, mas é construída nas relações sociais que são estabelecidas em cada cultura, podendo ser negociada, ressignificada e desconstruída.

As análises contribuem também para demonstrar a importância de intervenções pedagógicas com filmes e curtas-metragens que problematizem a construção da Branquitude na escola, de forma a desnaturalizar discursos e representações estereotipadas, que de tão arraigados na cultura são tomados como verdades, contribuindo para discriminações, exclusões e para a baixa autoestima de alunos e alunas considerados fora dos padrões de "normalidade". Neste sentido, salienta-se a importância da discussão sobre a Branquitude na escola básica, no sentido de tencionar e reverter práticas excludentes, produzindo e fazendo circular formas alternativas e positivas de representação das diferenças étnico-raciais. 


\section{Referências}

ABRAMOWICZ, A. As relações étnico-raciais e a sociologia da infância no Brasil: alguns aportes. In: BENTO, M. A. S. (Org.). Educação infantil, igualdade racial e diversidade: aspectos políticos, jurídicos, conceituais. São Paulo: Centro de Estudos das Relações de Trabalho e Desigualdades - CEERT, (p. 47-64). 2012.

ANDRADE, S. dos S. A entrevista narrativa ressignificada nas pesquisas educacionais pósestruturalistas. In: MEYER, D. E., PARAÍSO, M. A. (Org.). Metodologias de pesquisas póscríticas em educação. Belo Horizonte: Mazza Edições, 2012.

BRASIL. Lei 10.639, de 09 de janeiro de 2003 - altera a Lei n. 9.394, de 20 de dezembro de 1996, que estabelece as diretrizes e bases da educação nacional, para incluir no currículo oficial da Rede de Ensino a obrigatoriedade da temática "História e Cultura AfroBrasileira”, e dá outras providências. Diário Oficial da União, Brasília, DF, o9 de jan. 2003.

BRASIL. Lei 13.006, de 26 de junho de 2014 - acrescenta o parágrafo $8^{\circ}$. ao art. 216 da lei n. 9.394, de 20 de dezembro de 1996, que estabelece as diretrizes e bases da educação nacional, para obrigar a exibição de filmes de produção nacional nas escolas de educação básica. Diário Oficial da União, Brasília, DF, 26 jun. 2014.

CARDOSO, L. O branco ante a rebeldia do desejo: um estudo sobre a Branquitude no Brasil. São Paulo, 2014. 290p. Tese (Doutorado em Ciências Sociais). Universidade Estadual Paulista Júlio de Mesquita Filho.

Cores e Botas [curta-metragem]. Direção e roteiro: Juliana Vicente, Produção: Juliana Vicente, Nalu Béco Empresa Preta Portê Filmes. São Paulo, SP. 2010. Disponível em: https://www.youtube.com/watch?v=DLR22yNX4zU\&t=36s. Acesso em: 03 fev. 2018.

DUARTE, R. A pedagogia da imagem fílmica: filmes como objeto de pesquisa em Educação. Cadernos de Antropologia e Imagem, Rio de Janeiro, v.10, n.1, p. 103-124, 2000.

DUSCHATZKY, S., SKLIAR, C. O nome dos outros: narrando a alteridade na cultura e na educação. In: LARROSA, J.; SKLIAR, C. (Orgs.). Habitantes de Babel: políticas e poéticas da diferença. Belo Horizonte: Autêntica, 2001.

GOMES, N. L. Diversidade étnico-racial e Educação no contexto brasileiro: Algumas reflexões. In: (Org.). Um olhar além das fronteiras: educação e relações raciais. Belo Horizonte: Autêntica, 2007. p. 97-109.

GOMES, N. L. Sem perder a raiz: corpo e cabelo como símbolos da identidade negra. Belo Horizonte: Autêntica, 2008. 
GUIZZO, B. S. “Aquele negrão me chamou de leitão!”: representações e práticas corporais de embelezamento na Educação Infantil. Porto Alegre, 2011. Tese (Doutorado em Educação). Universidade Federal do Rio Grande do Sul

HALL, S. A identidade cultural na pós-modernidade. Tradução: Tomaz Tadeu da Silva, Guacira Lopes Louro. Rio de Janeiro: DP\&A, 2011.

HALL, S. Cultura e representação. Org. e rev. téc. Artur Ituassu; trad. Daniel Miranda e Willian Oliveira. Rio de Janeiro: PUC - Rio, Apicuri, 2016.

PINHO, P. de S. Reinvenções da África na Bahia. São Paulo: Annablume, 2004.

PIZA, E. Branco no Brasil? Ninguém sabe, ninguém viu .... In: GUIMARÃES, A. S., HUNTLEY, A. L. (Org.). Tirando a máscara: ensaios sobre o racismo no Brasil. São Paulo: Paz e Terra, 2000.

Pode me chamar de Nadí [curta-metragem]. Direção e roteiro: Déo Cardoso. Produção executiva: Tamylka Viana Gente Nossa Filmes. Ceará, BA. 2009. Disponível em: https://www.youtube.com/watch?v=HNmizIrjQKU\&t=6s. Acesso em: 03 fev. 2018.

SCHUCMAN, L. V. Entre o “encardido", o "branco" e o "branquíssimo": Branquitude, Hierarquia e Poder na Cidade de São Paulo. São Paulo: Annablume, 2012.

SHOHAT, E., STAM, R. Crítica da imagem eurocêntrica: multiculturalismo e representação. São Paulo: Cosac Naify, 2006.

SILVA, T. T. Documentos de identidade: uma introdução às teorias do currículo. Belo Horizonte: Autêntica, 2000.

SILVEIRA, R. M. H. A entrevista na pesquisa em educação: uma arena de significados. In: COSTA, M. V. (Org.). Caminhos Investigativos II: outros modos de pensar e fazer pesquisa em educação. 2. ed. Rio de Janeiro: Lamparina Editora, 2007.

SOVIK, L. Aqui ninguém é branco. Rio de Janeiro: Aeroplano, 2009.

Recebido em: 18/09/2019 Aprovado em: 05/02/2020

Universidade do Estado de Santa Catarina - UDESC Centro de Ciências Humanas e da Educação - FAED

Revista PerCursos

Volume 20 - Número 44 - Ano 2019 revistapercursos@gmail.com 